\title{
Polarization Eh? Ideological Divergence and Partisan Sorting in the Canadian Mass Public
}

\author{
Eric Merkley \\ University of Toronto \\ eric.merkley@utoronto.ca \\ Forthcoming at Public Opinion Quarterly
}

There has been increasing concern among commentators and scholars about polarization in Canada. This note uses the Canadian Election Study from 1993-2019 to measure trends in ideological divergence, ideological consistency, and partisan-ideological sorting in the Canadian mass public. It finds only mixed evidence that Canadians are diverging ideologically and becoming more polarized - ideological distributions are unimodal and trends towards more dispersion are slight and driven entirely by the last two election cycles. Canadians are, however, becoming modestly more ideologically consistent and much more sorted - that is, partisanship, ideological identification, and policy beliefs are increasingly interconnected. These findings call for additional research on the causes and consequences of mass polarization in Canada and further efforts to situate these results, along with findings from the United States, in a comparative context.

Author Note: The author is appreciative of helpful comments provided by Chris Cochrane, Richard Johnston, Nick Ruderman and members of the Policy, Elections, and Representation Lab in the Munk School of Public Policy \& Global Affairs at the University of Toronto. The author thanks Kala Bryson as well for exceptional research assistance. This work was supported by the Social Sciences and Research Council of Canada [756-2020-0694]. The author declares they have no conflicts of interest. *Address correspondence to Eric Merkley, University of Toronto, Department of Political Science, Sidney Smith Hall Room 3018, 100 St. George Street, Toronto, ON, Canada, M5S 3G3. 
Over the last few years commentators have increasingly embraced the notion that Canadians are in the grips of a polarization epidemic. ${ }^{1}$ But any evaluation of mass polarization has to wrestle with the fact that there are different dimensions of this phenomenon. Mass publics may exhibit polarization on some dimensions, but not on others, and this may have implications for the political and social costs that this process imposes on society.

One common conceptualization of polarization involves the clustering of citizens on left-right ideological poles (Fiorina, Abrams and Pope 2005, 2008; Fiorina and Abrams 2008), which has been labeled ideological divergence (Lelkes 2016). We might observe increasingly bimodal - or at least dispersed - distributions of ideology if mass publics are diverging ideologically and becoming more extreme.

But one may also see polarization as a process of ideological alignment where partisanship, ideology, and issue preferences become increasingly correlated with one another (Abramowitz and Saunders 2008; Abramowitz 2010). This can occur irrespective of whether or not citizens are becoming more ideologically extreme (Levendusky 2009). Along these lines, we may see higher levels of ideological consistency, where issue preferences become more internally consistent and highly correlated over time (Abramowitz and Saunders 2008; Baldassarri and Gelman 2008; Abramowitz 2010; Kozlowski and Murphy 2021) or partisan-ideological sorting, where policy beliefs and ideology become increasingly intertwined with partisanship (Abramowitz 2010; Abramowitz and Saunders 2008; Levendusky 2009).

The above conceptualizations of polarization involve ideology and policy beliefs, but polarization need not implicate ideology. Mass publics may also exhibit social polarization or social sorting where social groups and identities, like race, religion, or class, become increasingly correlated with partisan identity (Mason 2018). And most notably, we may observe polarization in feelings towards political opponents - both parties and their supporters - known as affective polarization (Iyengar, Sood and Lelkes 2012). Efforts to clearly delineate these distinct dimensions of polarization have been limited to date (for an important exception, see Lelkes 2016). This is especially true outside of the American context.

Canada presents an interesting case for the study of mass polarization. One of the factors most commonly associated with this phenomenon is on the rise in Canada: elite polarization (Levendusky 2009). Once having had a long tradition of electoral dominance by non-ideological brokerage parties (Carty, Cross and Young 2001; Johnston 2017), Canada's two major parties began to polarize in the 1980s. The Conservative Party and its predecessors moved to the right, while the Liberal Party moved to the left (Cochrane 2015). The old brokerage model of politics no longer holds quite as well in Canada.

\footnotetext{
${ }^{1}$ Supplementary Material, Figure S1 shows a rise in news articles about polarization in Canadian politics in the big three Canadian newspapers: the Globe and Mail, the Toronto Star, and the National Post.
} 
At the same time, Canada's political context has other features that may cut against mass polarization. It has a multi-party system with one traditionally dominant centrist party (i.e., the Liberal Party), a historically weak centre-left party (i.e., the New Democratic Party), and regional or provincial protest parties that vary over time and across provinces (e.g., the Bloc Quebecois and the Reform Party). This reflects the pervasive importance of regionalism and the federalist-sovereigntist dimension in Canadian politics.

We do not yet have a complete picture of the nature and dynamics of mass polarization in Canada. Johnston (2014) finds little evidence of ideological divergence using left-right placement scales between 2004 and 2011. There is more evidence of partisan-ideological sorting. Kevins and Soroka (2018) find that vote choice and partisanship have become increasingly correlated with responses to policy-based questions related to redistribution. The social dimension of polarization has gone unexplored, likely to do a lack of suitable over time indicators.

More conclusive is evidence of affective polarization, at least between supporters of centreright and centre-left parties. Conservative partisans increasingly dislike the Liberal Party, while Liberal and NDP supporters are more hostile to the Conservative Party (and its predecessors), as found by feeling thermometers (Cochrane 2015), mirroring patterns of elite polarization. In fact, Canada is one of only a few countries undergoing affective polarization based on cross-nationally comparable measures (Boxell, Gentzkow and Shapiro 2021).

In this note I aim to provide a comprehensive accounting of the degree of polarization in the Canadian public. I set aside affective polarization since it has been covered elsewhere (Cochrane 2015; Johnson 2019). I am also unable to address social polarization because of a lack of suitable questions that are available over time. I therefore focus my attention on the ideological dimensions of mass polarization: ideological divergence, ideological consistency, and partisan-ideological sorting.

\section{Data and Methods}

I measure ideological divergence, ideological consistency, and partisan-ideological sorting using the Canadian Election Study (CES) from 1993 to 2019. Perhaps the most straightforward measure we can examine is the 0-10 ideological self-placement scale. This question was asked first in the 1997 CES, and then from 2004 onward. However, these questions tap into ideological identity rather than policy-based ideology. There is often a fair amount of slippage between the policies people support and the ideology they claim to possess (Kinder and Kalmoe 2017).

The CES contains a number of broad policy questions that can also be used to measure ideology. I identified eight questions that have been asked consistently since 1993. The question wordings can be found in the Supplementary Material. Although the questions themselves have remained constant, their placement has varied between the campaign period survey, the postelection survey, and the mail-back survey components of the CES. The CES changed substantially in 2019, including both an online survey with a non-probability sample and a nationally representative phone survey with no mail-back component. More details on sample characteristics and response rates can be found in the Supplementary Material. 
I create three measures of ideology from these items. First, I rescale each policy item from 0-1 where 1 is the most right-wing response and create an additive index of left-right policy-based ideology. Then, I use exploratory factor analysis to identify dimensions that run through these eight items. They load on two factors that approximate attitudes towards social and economic policy. The factor loadings and the results of both a scree plot and parallel analysis can be found in Supplementary Material, Table S1 and Figures S2 and S3.

A mass public characterized by ideological divergence is one in which individuals move towards more extreme left-wing or right-wing ideological identification and policy beliefs, such that their distributions become increasingly bimodal. Consequently, I calculate the bimodality coefficient for ideological self-placement, policy-based ideology, and the two dimensions of ideology generated from the factor analysis. The bimodality coefficient (BC) is calculated as follows:

$$
B C=\frac{s^{2}+1}{k+3 * \frac{(n-1)^{2}}{(n-2)(n-3)}}
$$

where $s$ represents the skewness of the distribution, $k$ refers to its excess kurtosis and $n$ is the sample size. A BC of 1 indicates a completely bimodal distribution, while a score of 0 indicates a completely unimodal distribution. Bimodality is typically reached past 0.55 on this scale. ${ }^{2}$ The policy items identified above can also be used to measure levels of ideological consistency as well. I simply observe whether the average pairwise correlation between these items has gone up over time.

I measure partisan sorting by evaluating the distinctiveness of the ideological distributions for Liberal, NDP, and Conservative partisans (or both Reform/Alliance and Progressive Conservative partisans before the creation of the Conservative Party of Canada in 2004). Identifying partisanideological sorting in the U.S. is relatively straightforward: we should observe, and do observe (see Lelkes 2016), more ideological dissimilarity between Democratic and Republican identifiers over time. Expectations are more complex in Canada, with one historically left-wing party (the New Democratic Party (NDP)) and two non-ideological brokerage parties, the Liberals and the Conservatives, with the former firmly planted at the ideological center.

As noted, we have seen an erosion of the brokerage model in Canada, as the Conservative and Liberal parties have moved towards the ideological poles (Cochrane 2015). We might then expect their supporters to follow suit. Expectations for NDP supporters are less clear, since the NDP have always been positioned clearly on the centre-left.

\footnotetext{
${ }^{2}$ Bimodality coefficients, however, are imperfect tool to evaluate the bimodality of distributions, with values often being inflated by high skewness (see Pfister et al. 2013). So I also provide the standard deviations of ideological self-placement, policy-based ideology, and the two ideological dimensions in the Supplementary Material, Figure S4.
} 
I use the distinctiveness coefficient (DC), following Levendusky and Pope (2011) and Lelkes (2016):

$$
D C=1 / 2 \int_{-\infty}^{+\infty}|f(x)-d(x)| d x,
$$

Where $\mathrm{f}(\mathrm{x})$ represents the distribution of ideology for one group of partisans, and $\mathrm{d}(\mathrm{x})$ represents the distribution for the other group. In this case there will be three pairs of partisan groupings (Liberals and Conservatives, Liberals and NDP, and NDP and Conservatives). A DC of 1 indicates completely distinct distributions, while 0 represents perfect overlap.

If Liberals and Conservatives are moving to the left and right, respectively, we should see increasing DCs for that party pair. We should also observe growing DCs for the NDP and Conservatives. We might also see decreasing DCs for the NDP and Liberals if the former remain in a similar ideological location, owing to their historical status as an ideological third party.

(A) Ideological self-placement

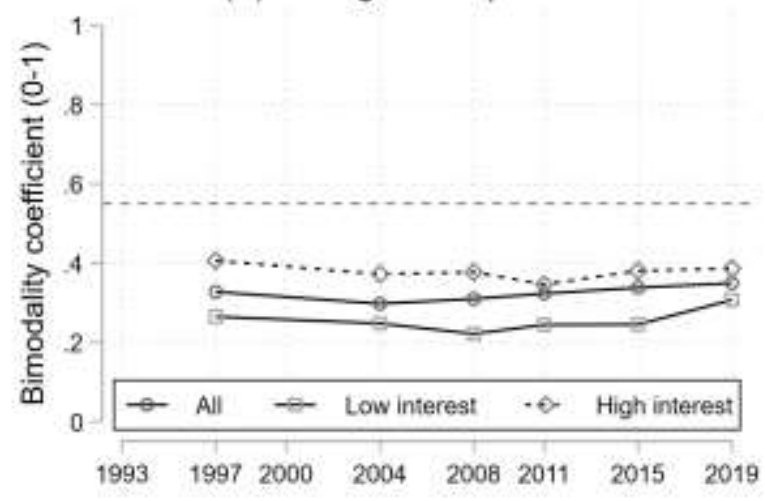

(C) Social policy

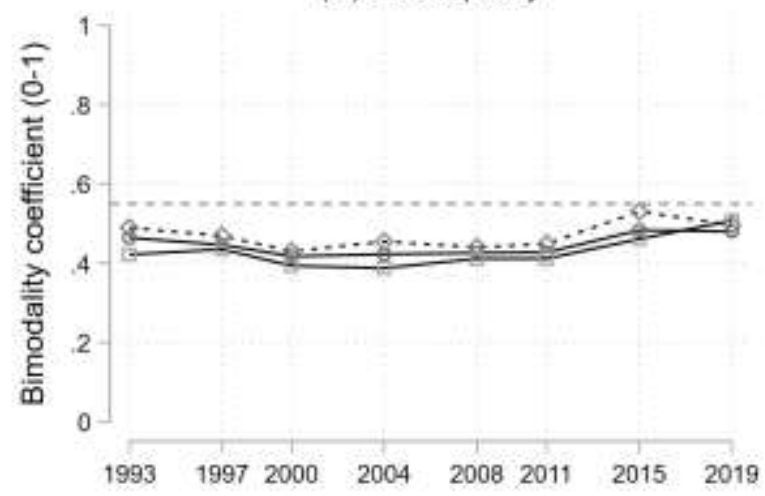

(B) Policy-based ideology

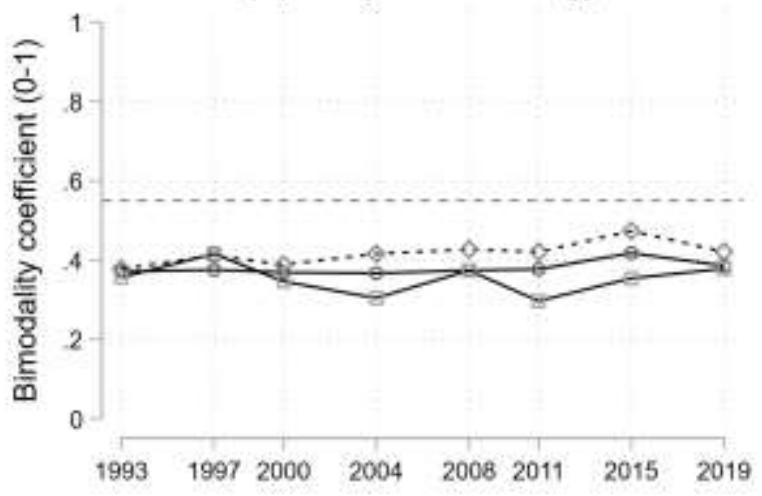

(D) Economic policy

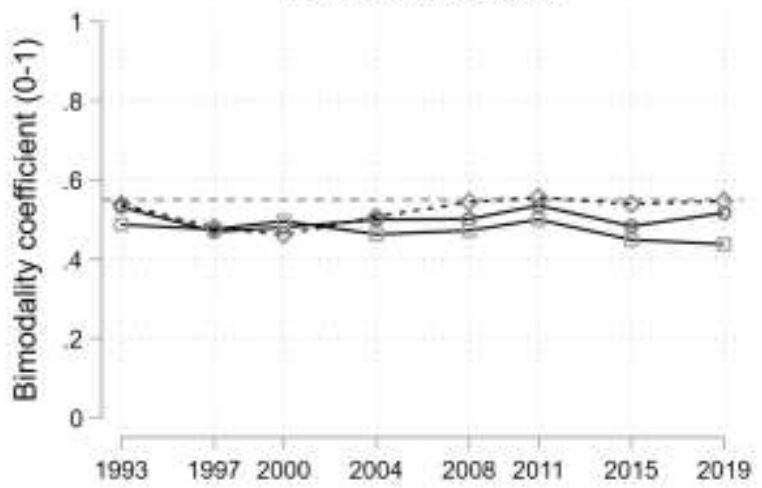

Figure 1. Ideological divergence in the Canadian Election Study. Bimodality coefficients of A) ideological self-placement; B) policy-based ideology; C) social policy attitudes; D) economic policy attitudes. 


\section{Results}

The bimodality coefficients, plotted in Figure 1, illustrate only minimal ideological divergence. For ideological self-placement (panel A), the BC increased 7\% between 1997 and 2019 (0.33 to 0.35). It is possible that certain subsets of respondents may have become more polarized in their responses even if the broader public has not. For instance, individuals with high levels of political interest could have become more polarized since they are more attuned to political discourse. But, the $\mathrm{BC}$ increased by $16 \%$ for those with low levels of political interest $(0.26$ to 0.31$)$ and decreased $5 \%$ for those of high political interest (0.41 to 0.39).

The BC for policy-based ideology also increased slightly by 4\% from 1993 to 2019 (0.37 to 0.39). We see a larger $11 \%$ increase for those of high political interest (0.38 to 0.42$)$ compared to a modest $6 \%$ for those of low interest. The increase we see in the $\mathrm{BC}$ for highly interested respondents is not linear over time. The BC was as high as 0.41 in 1997 and remained approximately at this level until 2015. There is only minimal evidence of a pronounced and steady increase in ideological divergence. Moreover, the BCs are well below the 0.55 threshold that typically indicates bimodality.

The BCs for the social and economic ideological dimensions identified by the factor analysis are found in panels C and D. Again there is little evidence of divergence. There is virtually no difference in the bimodality coefficients for social policy between 1993 and 2019 (0.46 vs. 0.48) and even for those of high political interest $(0.49$ vs. 0.50$)$. The same is true of the economic policy dimension. ${ }^{3}$ We observe very similar findings using the standard deviations displayed in Supplementary Material, Figure S4.

$\underline{\text { Ideological consistency }}$

Canadians are not ideologically diverging at a meaningful rate, but they do appear to be more consistent in their beliefs, as shown in panel A of Figure 2. The average correlation between the eight issue questions has increased $127 \%$ between 1993 and 2019, from 0.12 to 0.28 . This is occurring both among politically interested and less interested respondents, though the increase for the latter has been principally over the last two election cycles. Although correlations between issue items has increased, they are still substantively modest.

\section{Partisan-ideological sorting}

There is even stronger evidence of partisan-ideological sorting. Panel B of Figure 2 plots the dissimilarity coefficient for ideological self-placement. Liberal and Conservative partisans have become increasingly dissimilar. Their DC has increased 64\%, from 0.23 in 1997 to 0.37 in 2019. Meanwhile Liberal and NDP partisans converged, with their DC dropping by $27 \%$, from 0.35 to

${ }^{3}$ The BCs for these dimensions do skirt the threshold of bimodality (i.e., 0.55), but visual inspection of the distributions reveal little indication of double-peakedness. The economic dimension is also highly skewed, thereby likely inflating the BCs (see Pfister et al. 2013). The distributions for the two extracted factors in 1993 and 2019 can be found in the Supplementary Material, Figure S5. 
0.26. NDP and Conservative partisans have stayed dissimilar in their ideological self-placement, though perhaps with an upward trend since 2004.
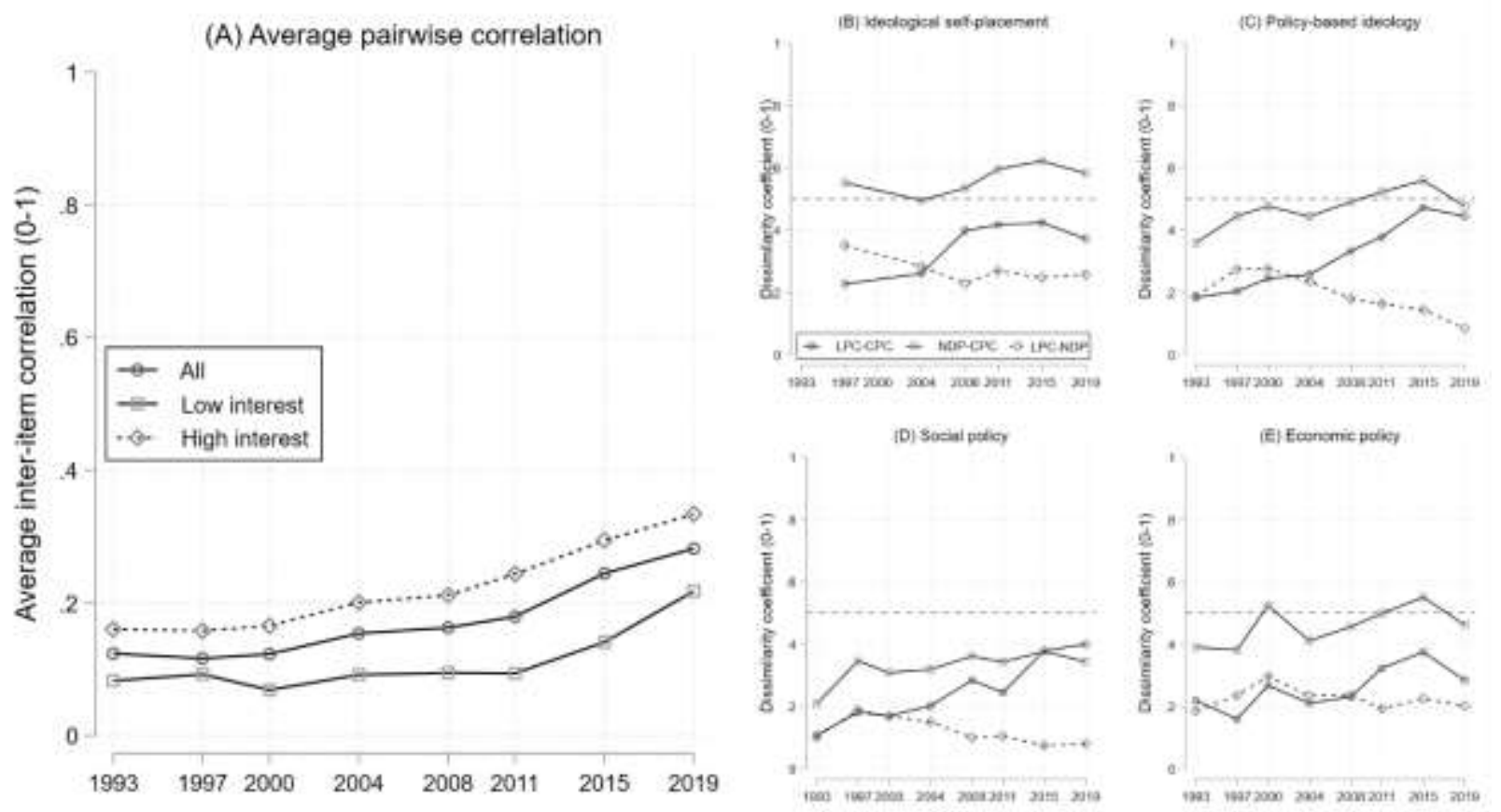

Figure 2. Average inter-item correlation (A). Partisan dissimilarity in (B) ideological self-placement; (C) policy-based ideology; (D) social policy; and (E) economic policy.

The same core finding emerges when looking at a measure of policy-based ideology (Panel C). Here, there appears to be an increasing divide between both the NDP and Liberals, on one hand, and Conservatives on the other. The DC for the NDP and Conservatives has gone up 33\%, from 0.36 in 1993 to 0.48 in 2019, while the DC for the Liberals and Conservatives has increased by 143\% over the same span, from 0.18 to 0.44 . In contrast, the DC for the Liberals and NDP has dropped $55 \%$, from 0.19 to 0.08 .

Panels D and E plot the DCs using the social and economic ideology dimensions that emerged from the factor analysis. The core pattern remains intact within each ideological dimension, though it is stronger for social policy. The DC for the social policy dimension increased by $65 \%$ for the NDP and Conservatives, from 0.21 to 0.34 , and by $270 \%$ for the Liberals and Conservatives, from 0.11 to 0.40 . The Liberals and the NDP have converged modestly from an already low baseline, with their DC dropping 57\%, from 0.19 to 0.08 between 1997 and 2019. On economic policy we also see increasing dissimilarity between the NDP and Conservatives, with the DC 
jumping 18\%, from 0.39 in 1993 to 0.46 in 2019. Liberals are also increasingly dissimilar from Conservatives, with their DC rising by $30 \%$, from 0.22 to $0.28 .^{4}$

Showing that ideological distributions of the Liberals and NDP are becoming more dissimilar from the Conservatives does not clearly tell us which partisan groups are moving to create that dissimilarity. Supplementary Material, Table S3 and Figure S6 illustrate mean changes in ideology across the three parties. Conservative partisans have shifted their ideological positioning to the right on average, especially for ideological self-placement. NDP ideological self-placement has remained steady, but they have shifted substantially to the left using the policy-based ideological measures. The Liberals have moved to the left sharply across the board.

\section{Discussion}

The aim of this paper is to provide an overview of the state of polarization in Canada. Canada is polarizing, but the nature of this polarization is nuanced. There is mixed evidence of increasing ideological divergence, or the gravitation of citizens to the ideological poles. Ideological distributions remain unimodal and we observe only a slight increase in the dispersion of ideological distributions over time. This increase is entirely driven by either the last election cycle or two, depending on the measure of ideology. It remains to be seen whether this reflects a new trend towards greater ideological polarization in Canada.

There is stronger and more robust evidence of rising ideological consistency and sorting in the Canadian public. That is, policy beliefs are becoming modestly more correlated with one another and much more correlated with partisanship. Particularly important is partisan sorting. There is increasing ideological dissimilarity between the Conservatives, on the one hand, and the Liberals and NDP on the other, mirroring patterns of affective and elite polarization. This trend appears to be most apparent in social policy.

Analyses in the Supplementary Material show that much of this is explained by significant movement of Liberal partisans to the left, but the Conservatives have also moved to the right, especially in ideological self-identification, while the NDP have moved to the left in policy-based ideology - a surprising development since the party had always taken on an ideological character. Ideology is now an important characteristic of partisan conflict - perhaps more so than at any point in Canadian history.

There are of course important limitations to the above analyses that need to be acknowledged. There are a limited number of policy questions asked continuously over time in the CES, while ideological identification is not asked as far back or as consistently as we might like. Further, these questions are often asked in post-election or mail-back re-contact waves that do not represent a representative sample of Canadians.

\footnotetext{
${ }^{4}$ The Supplementary Material provides plots that show: 1) dissimilarity coefficients for those of high and low political interest; 2) similar changes between Quebec and the rest-of-Canada (Tables S7-S9).
} 
Notwithstanding these caveats, these findings should provide a starting point for future research. For one, what caused partisan-ideological sorting in Canada? As Canadian political elites have also polarized (Cochrane 2015), this seems like a promising starting point. For another, is there a connection between partisan-ideological sorting and affective polarization in Canada? The dance of ideology, partisanship, and affect could lead to detrimental outcomes, liked biased information processing, heightened demand for partisan news, more social distance or alienation between partisan groups, and perhaps more contentious political discourse.

And perhaps most importantly, how does Canada compare cross-nationally on ideological dimensions of mass polarization? We know that partisan-ideological sorting is occurring in the U.S. (Fiorina and Abrams 2008; Levendusky 2009; Abramowitz 2010). Rising ideological consistency has been debated (Baldassarri and Gelman 2008; Abramowitz 2010), though more recent work has found stronger evidence of this process (Kozlowski and Murphy 2021). There remains substantial disagreement on the degree of divergence occurring in the U.S. public (Fiorina and Abrams 2008; Abramowitz 2010; Lelkes 2016).

In broad strokes, then, these findings are relatively consistent with what we see in Canada. But we lack survey measures to facilitate a precise comparison between these countries over time on these ideological dimensions of polarization, nor do we have this ability for social polarization deemed to be a crucial factor explaining affective polarization in the U.S. (Mason 2018) and the country's potential descent towards political sectarianism (Finkel et al. 2020). Ultimately, we need considerably more scholarly attention towards delineating and measuring different dimensions of mass polarization with the aim of facilitating cross-national comparison.

\section{Data Availability Statement}

Replication data and documentation are available at https://osf.io/5d23z/.

\section{References}

Abramowitz, Alan I. 2010. The Disappearing Center: Engaged Citizens, Polarization, and American Democracy. New Haven: Yale University Press.

Abramowitz, Alan I., and Kyle L. Saunders. 2008. “Is Polarization a Myth?” Journal of Politics 70:54255. doi:10.1017/S002238160808049

Baldassarri, Delia, and Andrew Gelman. 2008. "Partisans without Constraint : Political Polarization and Trends in American Public Opinion." The American Journal of Sociology 114:408-46. doi:10.1086/590649.

Boxell, Levi, Matthew Gentzkow, and Jesse M. Shapiro. 2021. "Cross-Country Trends in Affective Polarization.” NBER Working Paper 26669. National Bureau of Economic Research, Cambridge, MA. doi:10.3386/w26669.

Carty, Kenneth R., William P. Cross, Lisa Young. 2000. Rebuilding Canadian Party Politics. Vancouver: University of British Columbia Press. 
Cochrane, Christopher. 2015. Left and Right: The Small World of Political Ideas. Montréal: McGillQueen's University Press.

Finkel, Eli J., Christopher A. Bail, Mina Cikara, Peter H. Ditto, Shanto Iyengar, Samara Klar, Lilliana Mason, et al. 2020. "Political Sectarianism in America." Science 370: 533-36. doi:10.1126/science.abe1715.

Fiorina, Morris P., and Samuel J. Abrams. 2008. "Political Polarization in the American Public." Annual Review of Political Science 11:563-88. doi:10.1146/annurev.polisci.11.053106.153836.

Fiorina, Morris P., Samuel J. Abrams, and Jeremy C. Pope. 2005. Culture War? The Myth of a Polarized America. New York: Pearson Longman. . 2008. "Polarization in the American Public: Misconceptions and Misreadings." Journal of Politics 70:556-60. doi:10.1017/S002238160808050X

Iyengar, Shanto, Gaurav Sood, and Yphtach Lelkes. 2012. “Affect, Not Ideology: A Social Identity Perspective on Polarization.” Public Opinion Quarterly 76:405-31. doi:10.1093/poq/nfs059

Kevins, Anthony, and Stuart N. Soroka. 2018. "Growing Apart? Partisan Sorting in Canada, 19922015.” Canadian Journal of Political Science 51:103-33. doi:10.1017/S0008423917000713.

Kinder, Donald R., and Nathan P. Kalmoe. 2017. Neither Liberal nor Conservative: Ideological Innocence in the American Public. Chicago: University of Chicago Press.

Kozlowski, Austin C., and James P. Murphy. 2021. "Issue Alignment and Partisanship in the American Public: Revisiting the 'partisans Without Constraint' Thesis." Social Science Research 94. doi:10.1016/j.ssresearch.2020.102498.

Johnston, Richard. 2014. "Canada is Polarizing — and it's Because of the Parties." In Political polarization in American politics, edited by Daniel J. Hopkins and John Sides, 120-5. New York: Bloomsbury. Columbia Press. 2017. The Canadian Party System: An Analytic History. Vancouver: University British . 2019. "Affective Polarization in the Canadian Party System, 1988-2015." Paper presented at the Annual Meeting of the Canadian Political Science Association, Vancouver, BC.

Lelkes, Yphtach. 2016. “Mass Polarization: Manifestations and Measurements.” Public Opinion Quarterly 80:392-410. doi:10.1093/poq/nfw005.

Levendusky, Matthew S. 2009. The Partisan Sort: How Liberals Became Democrats and Conservatives Became Republicans. Chicago: University of Chicago Press.

Levendusky, Matthew S, and Jeremy C Pope. 2010. "Measuring Aggregate-Level Ideological Heterogeneity.” Legislative Studies Quarterly 35:259-82. doi:10.3162/036298010791170196. 
Mason, Lilliana. 2018. Uncivil Agreement: How Politics Became Our Identity. Chicago: University of Chicago Press.

Pfister, Roland, Katharina A Schwarz, Markus Janczyk, Rick Dale, and Jonathan B Freeman. 2013. "Good Things Peak in Pairs: a Note on the Bimodality Coefficient." Frontiers in Psychology 4. doi:10.3389/fpsyg.2013.00700. 


\section{Supplementary Materials}

\section{Polarization Eb? Ideological Divergence and Partisan Sorting in the Canadian Mass Public}

\section{Contents}

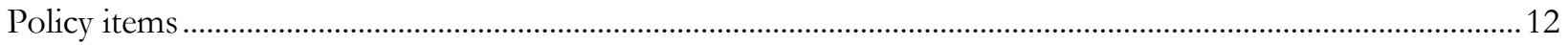

Sample characteristics.................................................................................................................................... 12

Table S1. Response and re-contact rates for the CES ........................................................................................ 13

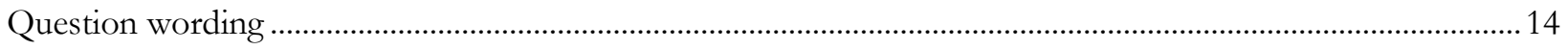

Table S2. Ideological items in the Canadian Election Study................................................................................ 18

Figure S1. Articles with keywords related to polarization featured in Canadian politics news ............................19

Figure S2. Scree plot from exploratory factor analysis. .....................................................................................20

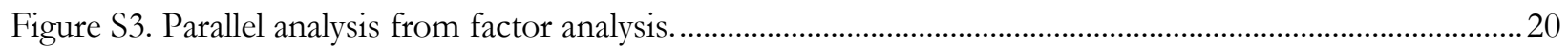

Figure S4. Standard deviations of ideological measures ...................................................................................21

Figure S5. Distributions of social (left) and economic policy over time (right). ...................................................22

Figure S6. Mean scores for ideological measures over time and by party ............................24

Figure S7. Liberal-Conservative dissimilarity coefficients across levels of political interest. ..............................24

Figure S8. Ideological divergence in Quebec and the Rest-of-Canada............................................................25

Figure S9. Quebec and Rest-of-Canada differences in the average inter-item correlation and partisan

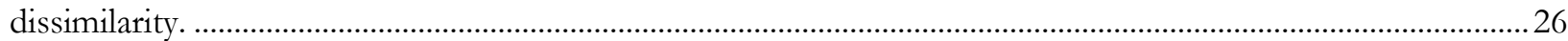

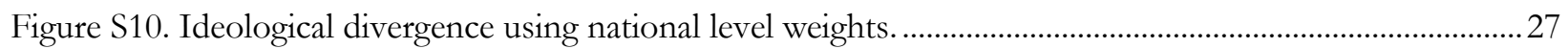

Figure S11. Standard deviations of ideological measures using national level weights .......................................22

Figure S12. Average inter-item correlation and partisan dissimilarity using national level weights. ..................28

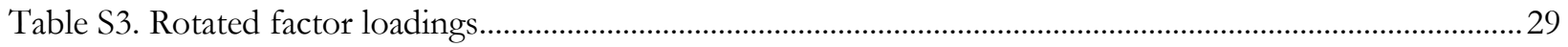

Table S4. Comparison of 2019 online and phone results for ideological self-placement ...................................22

Table S5. Mean ideological scores over time and by party....................................................................................... 30 


\section{Policy items}

- We have gone too far in pushing equal rights in this country

- Too many immigrants just don't want to fit into Canadian society

- The government should do more to reduce the income gap between the rich and the poor

- Protecting the environment is more important than creating jobs

- Homosexual couples should be allowed to legally marry ${ }^{5}$

- People who don't get ahead should blame themselves, not the system

- The government should: see to it that everyone has a decent standard of living; leave people to get ahead on their own

- Do you think Canada should admit more immigrants, fewer immigrants, or about the same as now?

\section{Sample characteristics}

Canadian Election Studies for the years 1993, 1997, 2000, 2004, 2008, 2011, 2015, and 2019 are used in this note due to the availability of consistently asked policy items and ideological selfidentification. These surveys were offered in English and French.

Until 2019, the CES was composed of three interlocking surveys. The Campaign Period Survey (CPS) is a rolling cross-sectional survey with sample divided equally into the set number of days in the writ period, the exact number of which varies election to election. The CPS uses a two stage probability selection process. The first stage uses Random Digit Dialing (RDD) to select telephone numbers. This procedure gives all households, not just those listed in telephone directories, an equal and known probability of selection. The second stage randomly selects potential respondents from that list of telephone numbers. The target population of the CES includes adult household members (18 years or older) who are Canadian citizens, speak one of two of Canada's official languages, reside within Canada's 10 provinces and 2 (or three depending on the election) territories and have a telephones. In the event of contact with multi-person eligible households, the adult who was reported to have the next birthday was interviewed.

Next, the Post-Election Survey (PES) involves re-contacts of respondents who completed the CPS, and finally there is a Mail-Back Survey (MBS) to those who completed the PES and provided their address. The ideology and policy issue questions that are central to the analysis presented here

\footnotetext{
${ }^{5}$ This question was omitted in the 2019 Canadian Election Study. It was replaced with a question asking respondents how much they think should be done for gay and lesbians (much more to much less, 5-pont).
} 
are found principally, though not exclusively, in the MBS. ${ }^{6}$ Below in Table A1 are the CPS response rates and completes, as well as the re-contact rates and completions for the PES and MBS for each election study used in this research note. The placement of each ideology and policy issue question can be found in Table A2.

There were some slight variations in the sampling procedure year to year. In 1993, 40\% of completes for the CPS were drawn from a panel of people who had completed a referendum survey the year before, while the remaining 60\% were contacted via RDD. The 2008 CES did not use a rolling-cross section design for its CPS. The CPS in this study includes fresh RDD sample, as well as re-contacts from the 2004 and 2006 surveys. The PES includes re-contacts from both the new sample, as well as re-contacts from 2006. The CPS for the 2011 CES includes $20 \%$ re-contacts from 2008 and 80\% new RDD sample. The MBS also includes of a web-based component with an otherwise identical survey, but the mail-back data is used exclusively here for consistency with prior waves.

Table S1. Response and re-contact rates for the CES

\begin{tabular}{ccccccc}
\hline & \multicolumn{2}{c}{ Campaign Period } & \multicolumn{2}{c}{ Post-election } & \multicolumn{2}{c}{ Mail-back } \\
& Response rate & Completes & Re-contact rate & Completes & Re-contact rate & Completes \\
\hline 1993 & $64 \%$ & 3,775 & $88 \%$ & 3,340 & $66 \%$ & 2,204 \\
1997 & $59 \%$ & 3,949 & $80 \%$ & 3,170 & $58 \%$ & 1,851 \\
2000 & $60 \%$ & 3,651 & $78 \%$ & 2,860 & $53 \%$ & 1,517 \\
2004 & $55 \%$ & 4,323 & $73 \%$ & 3,138 & $53 \%$ & 1,674 \\
2008 & $47 \%$ & 3,257 & $69 \%$ & 2,247 & $66 \%$ & 2,149 \\
2011 & $41 \%$ & 4,308 & $78 \%$ & 3,362 & $47 \%$ & 1,567 \\
2015 & $37 \%$ & 4,202 & $71 \%$ & 2,988 & $31 \%$ & 1,289 \\
\hline
\end{tabular}

The 2019 CES marked a dramatic change in survey mode and sampling procedure. Although the CES retained a telephone survey, it did not include the policy items used in this analysis, which are found in the online survey given to a non-probability sample from Qualtrics. This online survey set quotas for gender, age, and region. For gender they aimed for 50\% men and 50\% women. They targeted $28 \%$ to be aged 18-34, 33\% aged 35-54 and 39\% aged 55 and higher. The regions were: Atlantic (Newfoundland and Labrador, New Brunswick, Nova Scotia, Prince Edward Island), Quebec, Ontario Prairies (Manitoba, Saskatchewan, Alberta, and British Columbia).

\footnotetext{
${ }^{6}$ Before 2019, national weights for the Canadian Election Study were constructed for the CPS to correct sample estimates for the fact that single-member households were more likely to be contacted and smaller provinces were oversampled. These weights, however, were not designed for the less representative PES and MBS. As a result, estimates for 1993-2015 are unweighted in the main text. Supplementary Material, Figures S10-S12 provide the nationally-weighted estimates for ideological self-placement and policy-based ideology. The results are substantively identical.
} 
Within each of those regions, the provincial quotas were split evenly. They also aimed to have 80\% French and 20\% English within Quebec, 10\% French within the Atlantic region, and 10\% French nationally. Respondents needed to be over 18 years of age, and Canadian citizens or permanent residents - a different target population from previous iterations of the CES. They aimed for daily samples of 1,000 individuals. The CPS sample totally 37,822 individuals, with 10,337 successfully re-contacted for the PES (27\%).

I use the 2019 CES phone survey for 0-10 ideological self-placement since it is a nationally representative survey. I use the online survey for the policy-based ideological measures, since they are not included in the phone survey. The 2019 CES provides national weights by age, gender, education, language and region to correct national estimates for sampling bias. I employ these weights when using the online sample to allow for better comparability between the 2019 results and prior waves. The technical documentation for the CES between 1993 and 2019 can be found here: https://www.queensu.ca/cora/our-data/data-holdings.

Only the 0-10 ideological self-placement scale is included in the more representative phone survey in 2019. I use the phone survey for this item and the online survey for the three policy-based ideology measures. Supplementary Material, Table S2 provides a comparison of the 2019 phone and online results using the 0-10 ideological self-placement measure. There is more polarization in the online non-probability sample. We should therefore treat the 2019 results with caution, especially for the three measures of policy-based ideology.

\section{Question wording}

\section{Party identification}

In federal politics, do you usually think of yourself as a Liberal, Conservative, N.D.P, [Bloc Québécois if in Quebec] or none of these? [93]

Thinking of federal politics, do you usually think of yourself as a Liberal, Conservative, N.D.P, [Bloc Québécois if in Quebec] or none of these? [97]

In federal politics, do you usually think of yourself as: [00, split sample]

Generally speaking, in federal politics, do you usually think of yourself as a Liberal, Bloc Quebecois, Alliance, Conservative, NDP, or do you usually think of yourself as not having a general preference? [00, split sample]

Thinking of federal politics, do you usually think of yourself as a Liberal, Conservative, N.D.P, [Bloc Québécois if in Quebec] or none of these? [04, split sample]

In federal politics, do you usually think of yourself as a Liberal, Conservative, N.D.P, [Bloc Québécois if in Quebec], another party or no party? [04, split sample]

In federal politics, do you usually think of yourself as a Liberal, Conservative, [Bloc Québécois if in Quebec], Green Party, or none of these? [08, 11, 15] 
In federal politics, do you usually think of yourself as: [19]

$\underline{\text { Ideological identification }}$

In politics people sometimes talk of left and right. Where would you place yourself on the scale below? (0-10, not sure) [97, 04, 08, 11, 15]

In politics, people sometimes talk of left and right. Where would you place yourself on this scale? $(0$ 10, don't know) [19]

\section{Equal rights}

For each statement below, please indicate if you strongly agree, agree, disagree, or strongly disagree. "We have gone too far in pushing equal rights in this country" (strongly agree, agree, disagree, strongly disagree, no opinion [93], not sure [97, 00, 04, 08, 11, 15]).

How much do you agree or disagree with the following statements? "We have gone too far in pushing equal rights in this country" (strongly disagree, somewhat disagree, neither agree, nor disagree, somewhat agree, strongly agree, don't know). [19]

Assimilation

For each statement below, please indicate if you strongly agree, agree, disagree, or strongly disagree. "Too many recent immigrants just don't want to fit into Canadian society" (strongly agree, agree, disagree, strongly disagree, no opinion [93], not sure [97, 00, 04, 08, 11, 15]).

How much do you agree or disagree with the following statements? "Too many recent immigrants just don't want to fit into Canadian society" (strongly disagree, somewhat disagree, neither agree, nor disagree, somewhat agree, strongly agree, don't know). [19]

Inequality

For each statement below, please indicate if you strongly agree, agree, disagree, or strongly disagree. "The government must do more to reduce the income gap between rich and poor Canadians" (strongly agree, agree, disagree, strongly disagree, no opinion [93], not sure [97]).

How much should be done to reduce the gap between the rich and poor in Canada? (much more, somewhat more, about the same as now, somewhat less, much less, don't know). [00, 04, 08, 11]

For each statement below, please indicate if you strongly agree, agree, disagree, or strongly disagree. "The government should take measures to reduce differences in income levels" (strongly agree, agree, disagree, strongly disagree, not sure). [15]

How much do you agree or disagree with the following statements? "The government should take measures to reduce differences in income levels." (strongly disagree, somewhat disagree, neither agree, nor disagree, somewhat agree, strongly agree, don’t know). [19] 


\section{Environment}

For each statement below, please indicate if you strongly agree, agree, disagree, or strongly disagree. "Protecting the environment is more important than creating jobs" (strongly agree, agree, disagree, strongly disagree, no opinion [93], not sure [97, 00, 04, 08, 11, 15]).

How much do you agree or disagree with the following statements? "When there is a conflict between protecting the environment and creating jobs, jobs should come first." (strongly disagree, somewhat disagree, neither agree, nor disagree, somewhat agree, strongly agree, don't know). [19]

$\underline{\text { Same-sex marriage and related attitudes }}$

Could you tell me if you strongly agree, somewhat agree, somewhat disagree, or strongly disagree with the following statements: (strongly agree, somewhat agree, somewhat disagree, strongly disagree, don't know). [93]

For each statement below, please indicate if you strongly agree, agree, disagree, or strongly disagree. "Homosexual couples should be allowed to be legally married" (strongly agree, agree, disagree, strongly disagree, not sure). [97]

"Gays and lesbians should be allowed to legally marry" (strongly agree, somewhat agree, somewhat disagree, strongly disagree, don’t know). [00, 04, 08]

Do you favour or oppose same-sex marriage, or do you have no opinion on this? (favour, oppose, don't know/no opinion). [11, 15]

How much do you think should be done for gays and lesbians? (much more, somewhat more, about the same as now, somewhat less, much less, don't know) [19]

Blame themselves, not the system

For each statement below, please indicate if you strongly agree, agree, disagree, or strongly disagree. "Most people who don't get ahead should not blame the system; they have only themselves to blame" (Strongly agree, agree, disagree, strongly disagree, no opinion). [93]

Could you tell me if you strongly agree, somewhat agree, somewhat disagree, or strongly disagree with the following statements: "People who don't get ahead should blame themselves, not the system" (Strongly agree, somewhat agree, somewhat disagree, strongly disagree, don't know). [97, $00,04,08,11,15]$

How much do you agree or disagree with the following statements? "People who don't get ahead should blame themselves, not the system." (strongly disagree, somewhat disagree, neither agree, nor disagree, somewhat agree, strongly agree, don't know). [19]

\section{Standard of living}

The government should: 1) see to it that everyone has a decent standard of living; 2) leave people to get ahead on their own. [93, 97, 00, 04, 08, 11, 15, 19] 


\section{$\underline{\text { Immigration }}$}

Do you think Canada should admit more immigrants, fewer immigrants, or about the same as now? $[93,97,00,04,08,11,15,19]$ 
Table S2. Ideological items in the Canadian Election Study

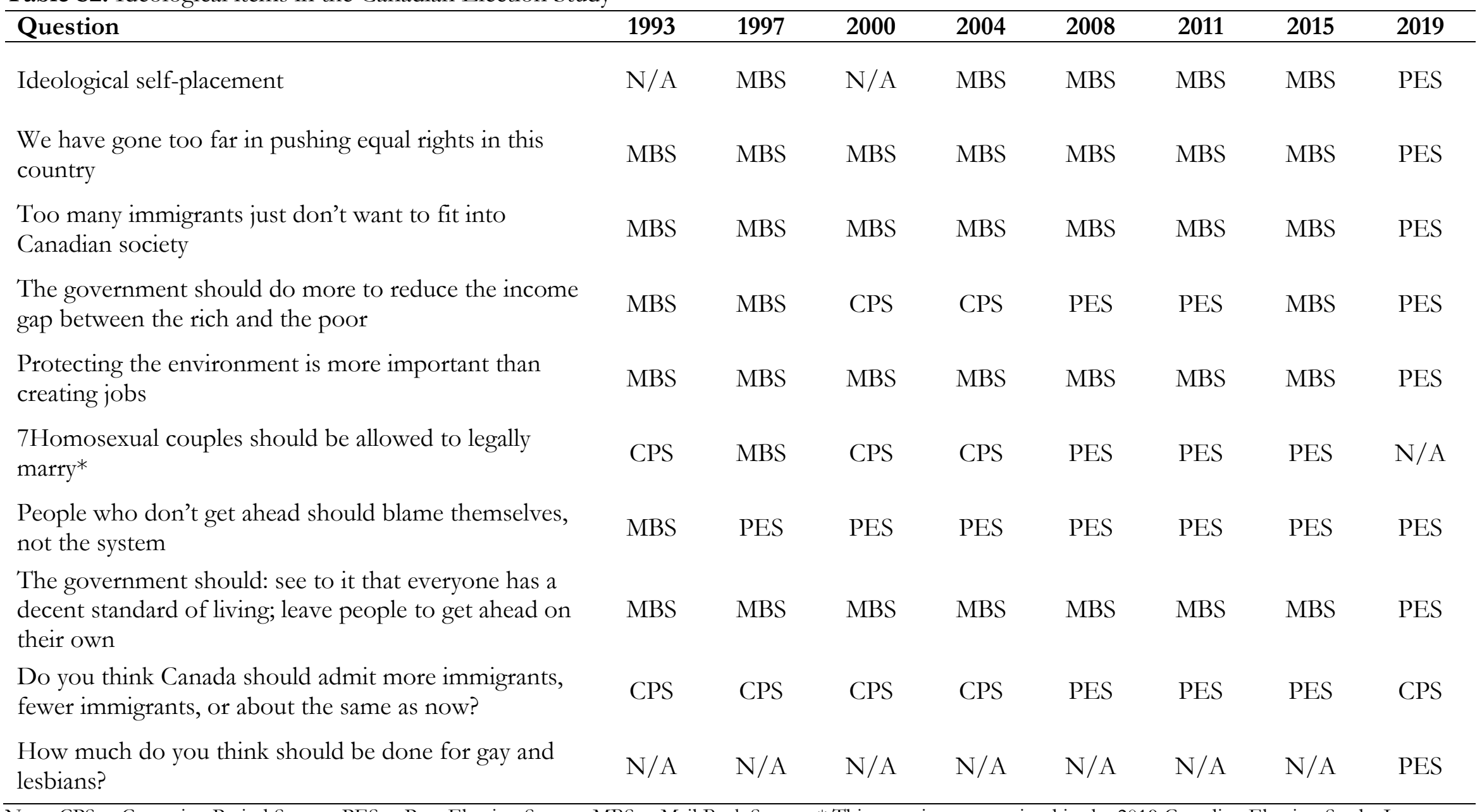

Note: CPS = Campaign Period Survey; PES = Post Election Survey; MBS = Mail Back Survey; * This question was omitted in the 2019 Canadian Election Study. It was replaced with a question asking respondents how much they think should be done for gay and lesbians (much more to much less, 5 -pont). Nonetheless, the 2019 results should be treated with caution due to this change and the different survey mode. In 2019 I use the phone survey for ideological self-placement. 


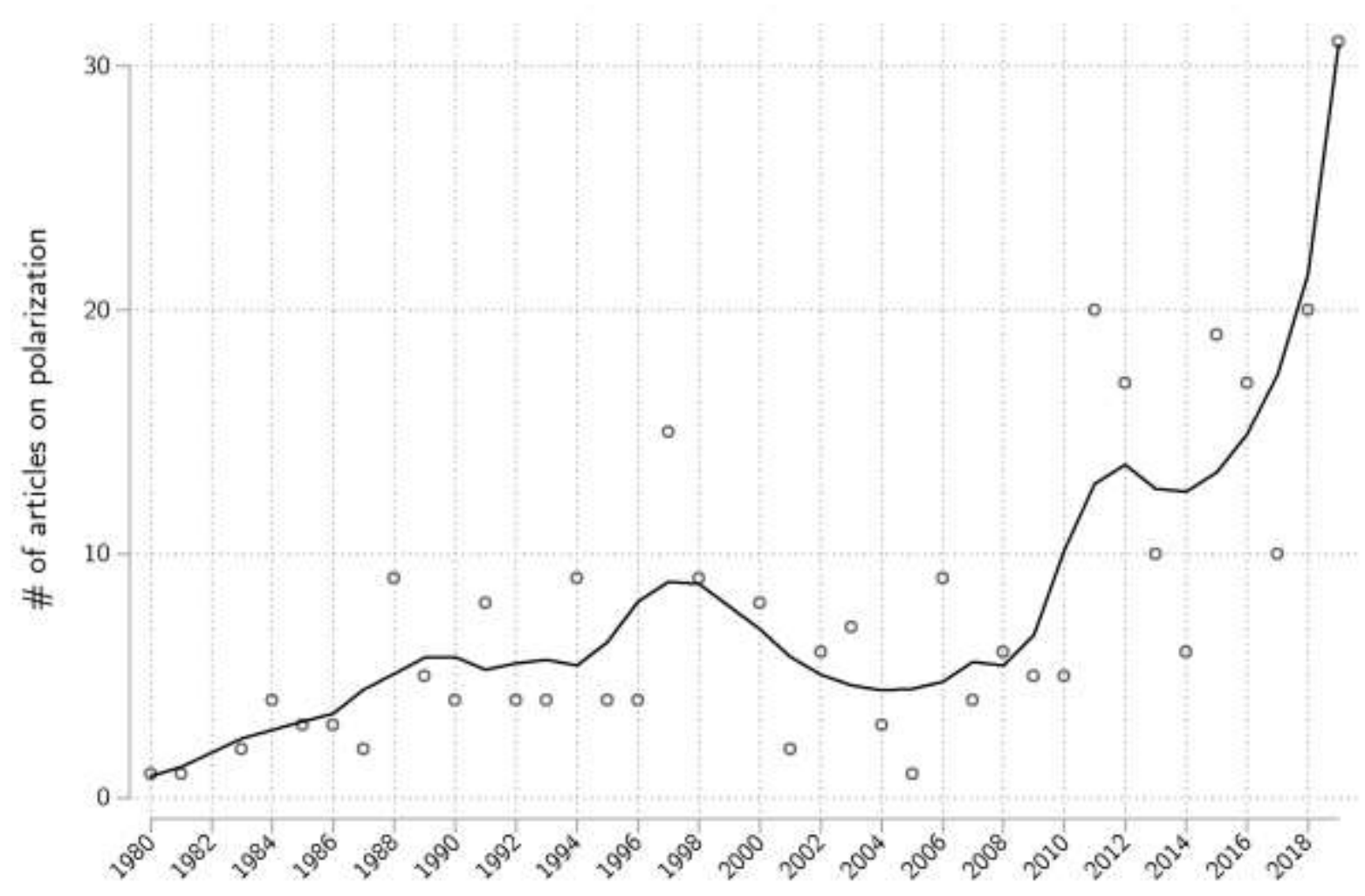

Figure S1. Number of articles with keywords related to polarization featured in the in Canadian politics news content in the Toronto Star, Globe and Mail, and National Post. Source: Lexis Uni. 


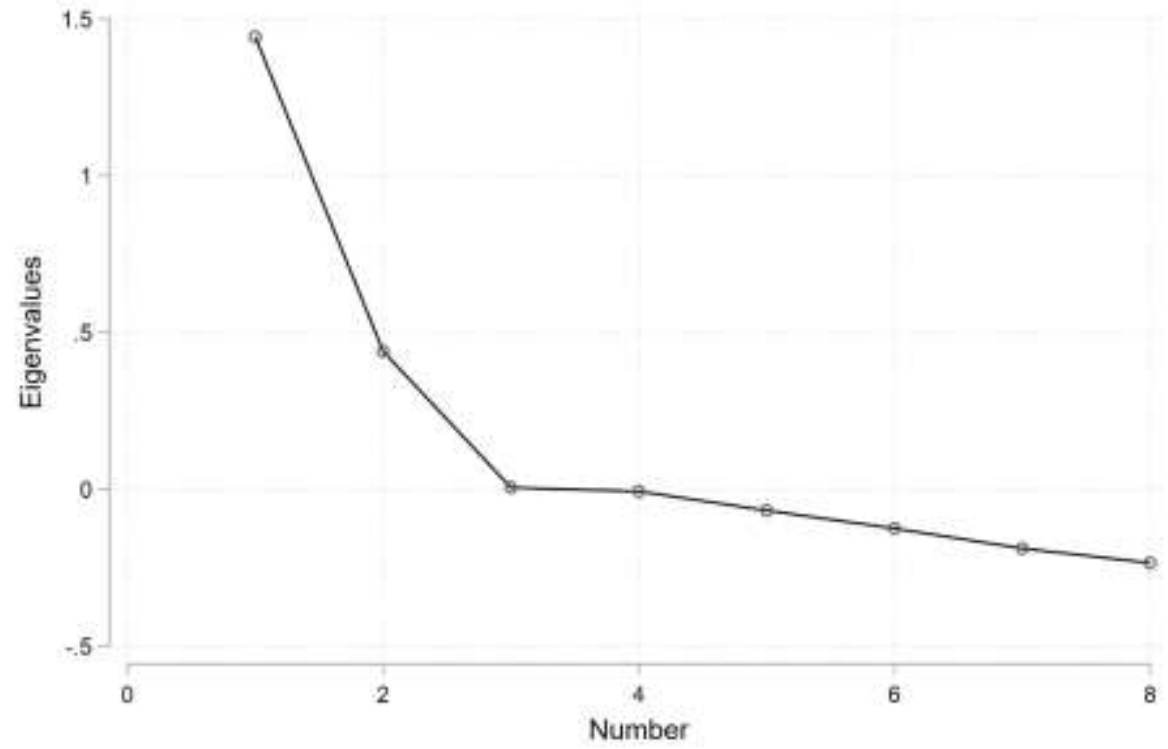

Figure S2. Scree plot from exploratory factor analysis. Plot shows the eigenvalues for each factor after rotation.

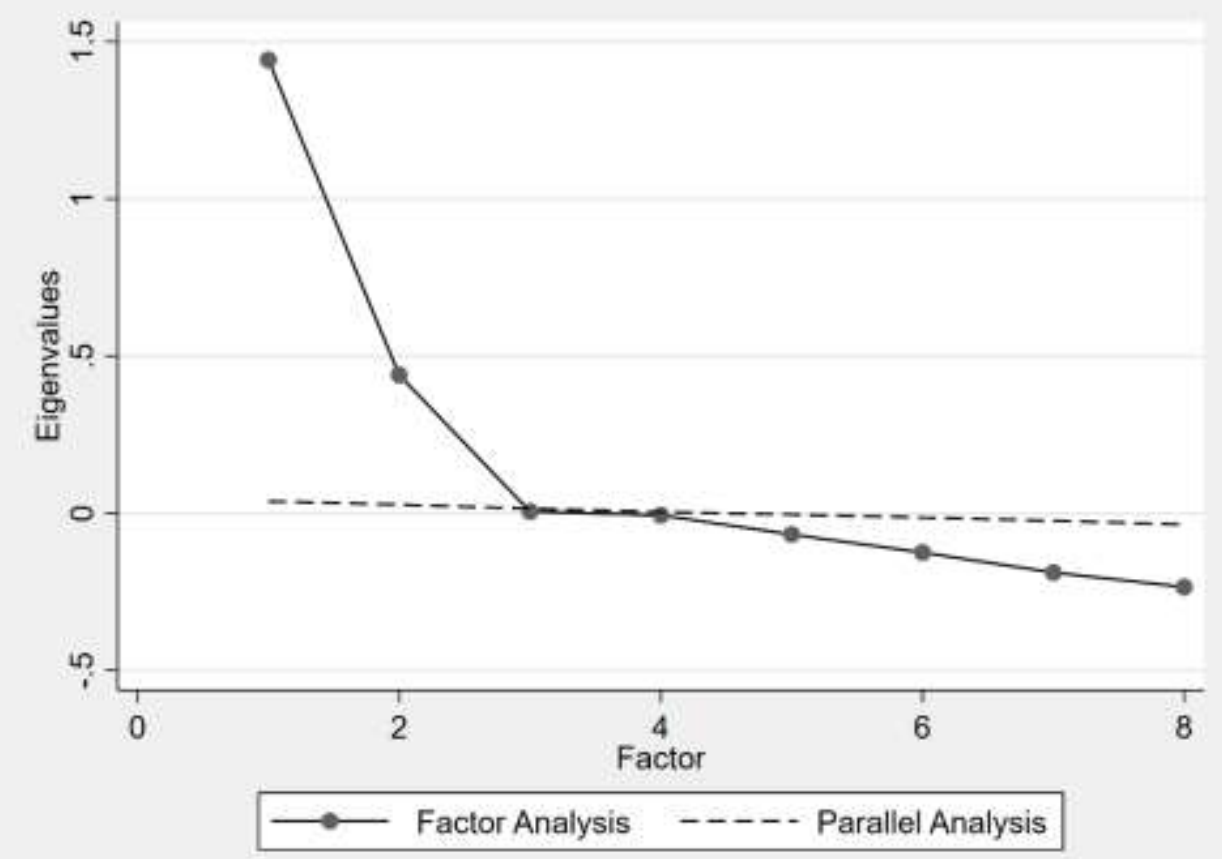

Figure S3. Parallel analysis from factor analysis. 

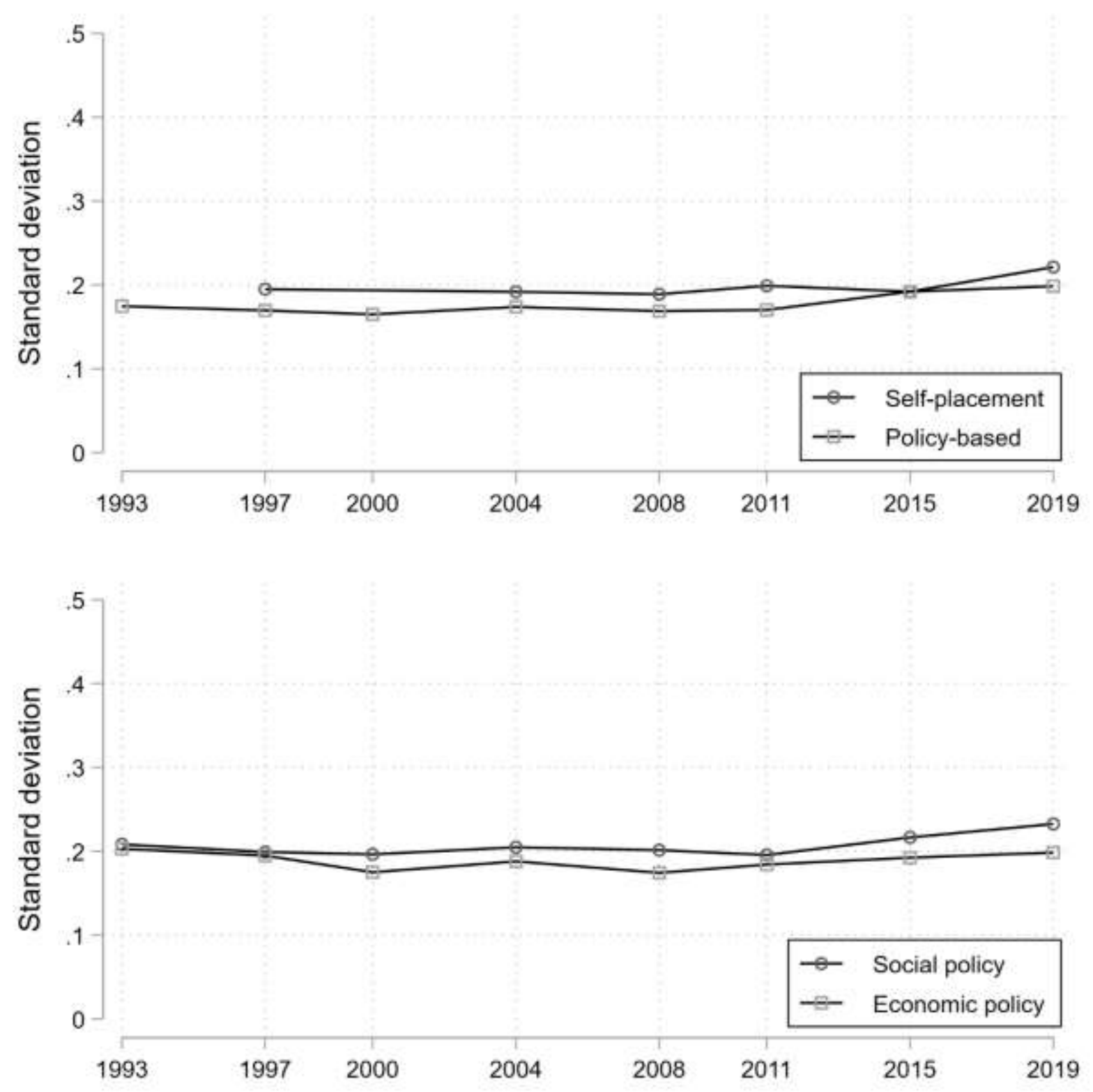

Figure S4. Standard deviations of (top) ideological self-placement and policy-based ideology; (bottom) social and economic policy attitudes. Each ideology measure rescaled from 0-1. 

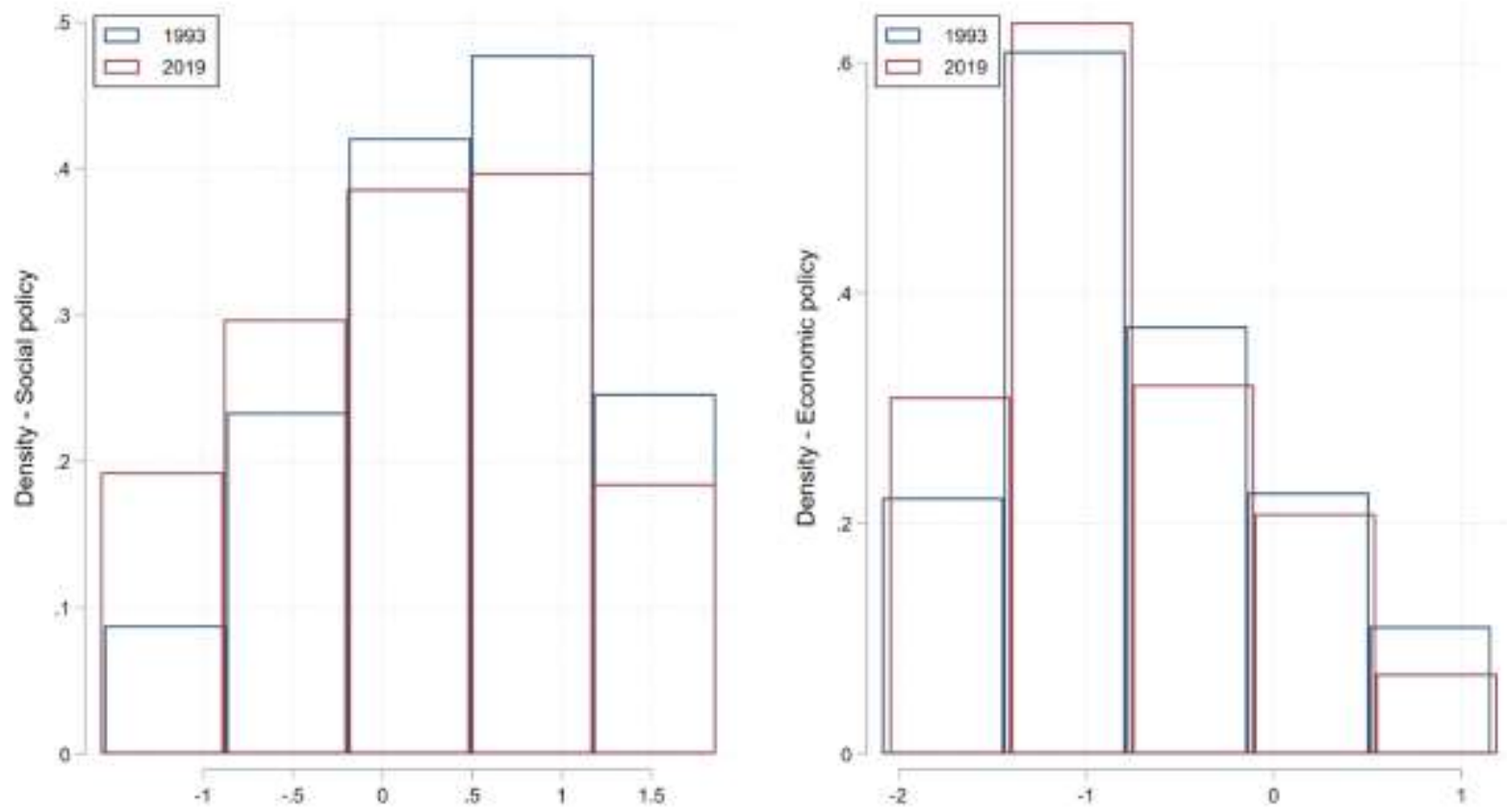

Figure S5. Distributions of social (left) and economic policy over time (right). 
(A) Ideological self-placement

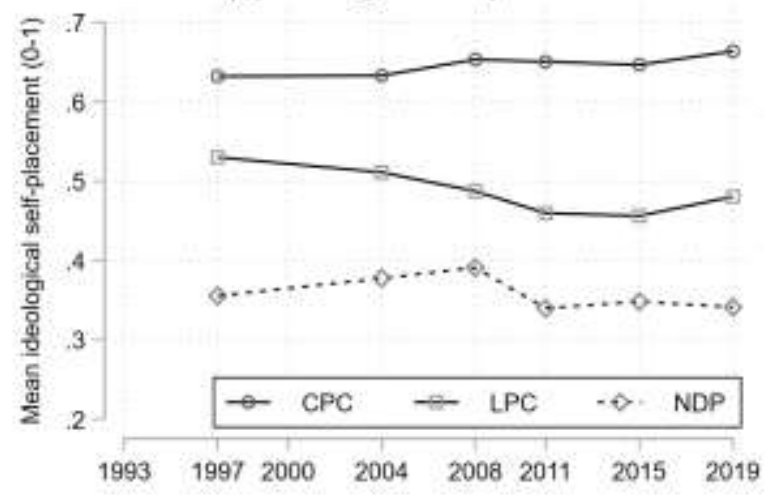

(C) Social

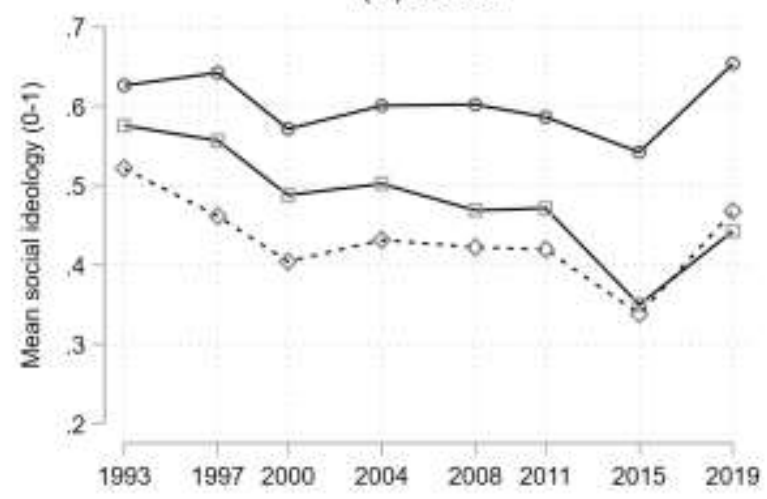

(B) Policy-based ideology

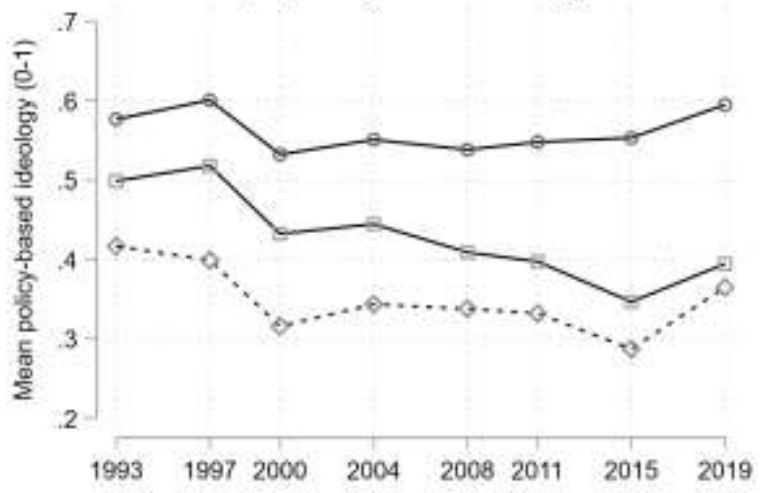

(D) Economic

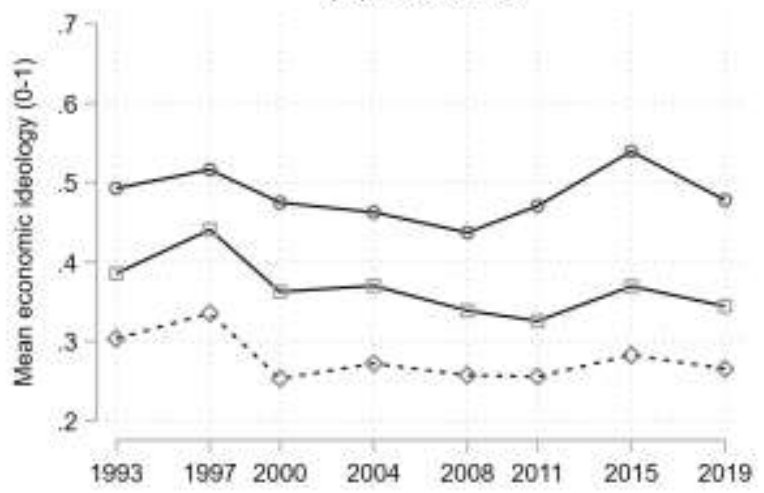

Figure S6. Mean scores by party for A) ideological self-placement; B) policy-based ideology; C) social policy attitudes; D) economic policy attitudes. 
(A) Ideological self-placement

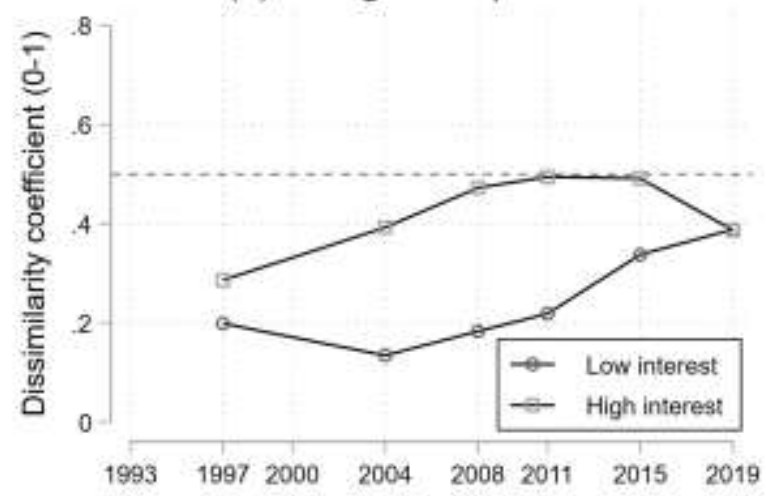

(C) Social policy

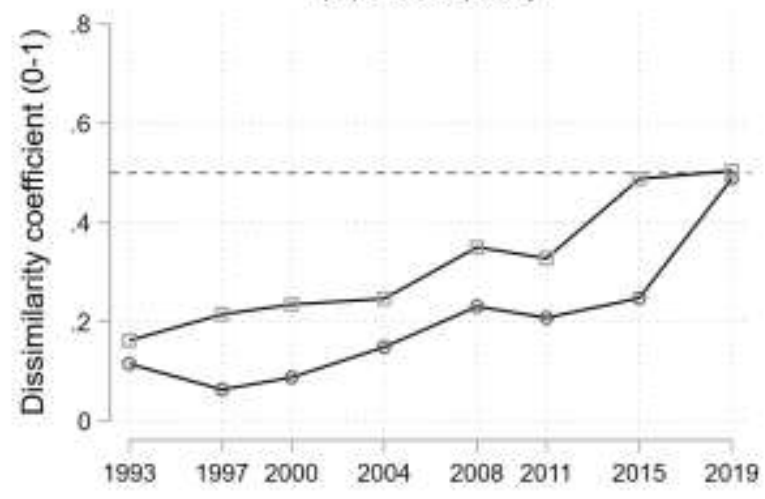

(B) Policy-based ideology

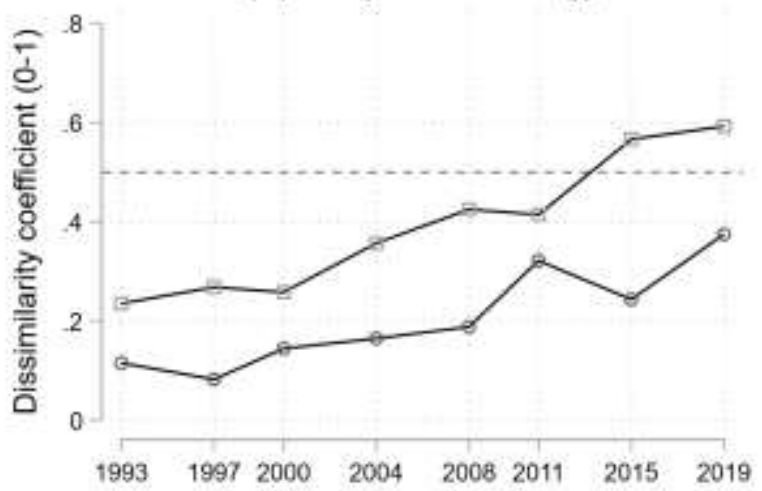

(D) Economic policy

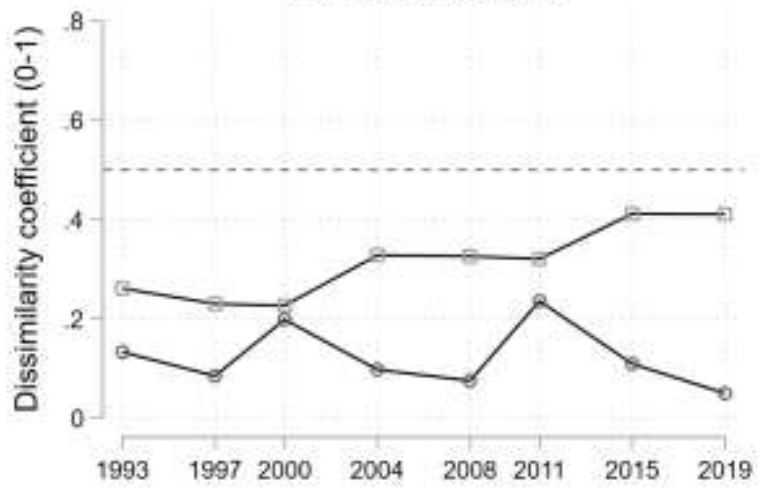

Figure S7. Liberal-Conservative dissimilarity coefficients for those of low and high political interest. Partisan dissimilarity in (A) ideological self-placement; (B) policy-based ideology; (C) social policy; and (D) economic policy. 
(A) Ideological self-placement

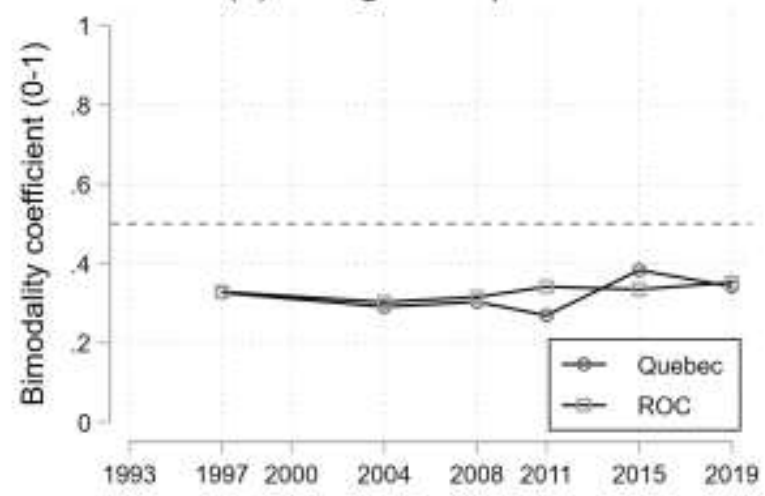

(C) Social policy

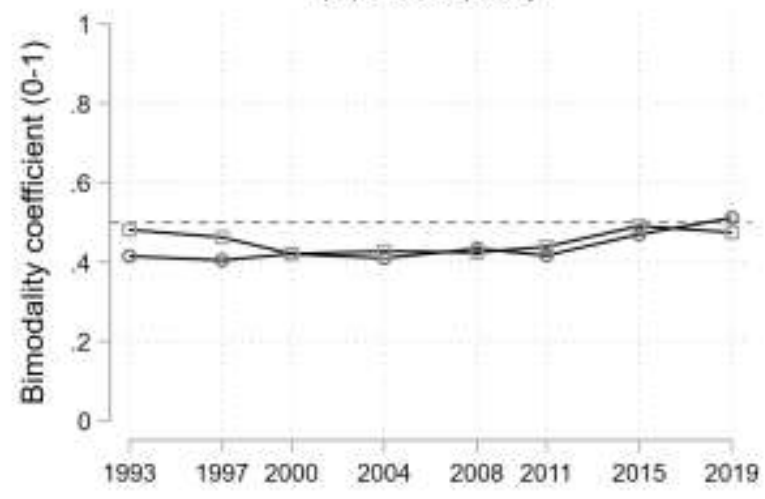

(B) Policy-based ideology

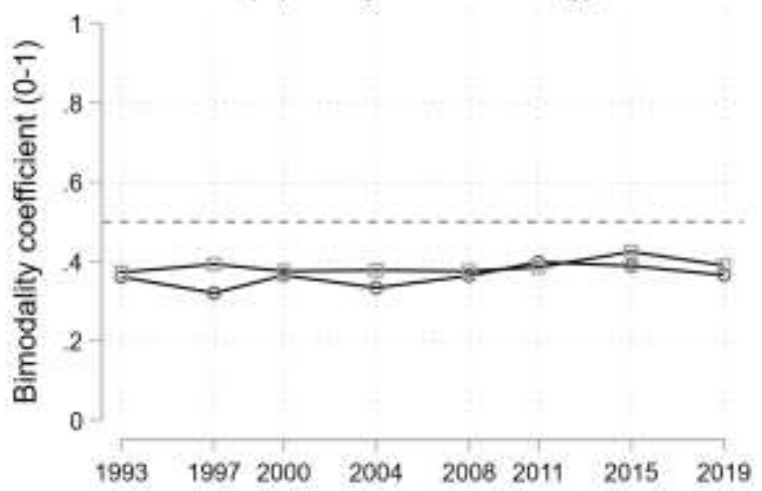

(D) Economic policy

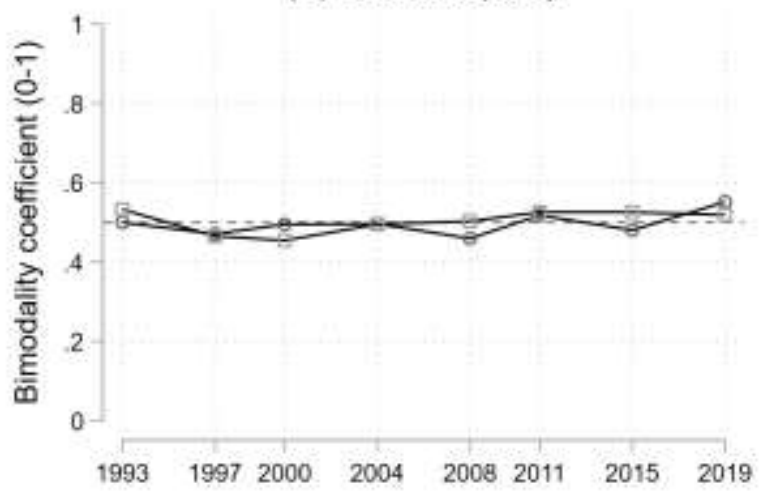

Figure S8. Ideological divergence in Quebec and the Rest-of-Canada. Bimodality coefficients of (A) ideological self-placement; (B) policy-based ideology; (C) social policy attitudes; and (D) economic policy attitudes. 

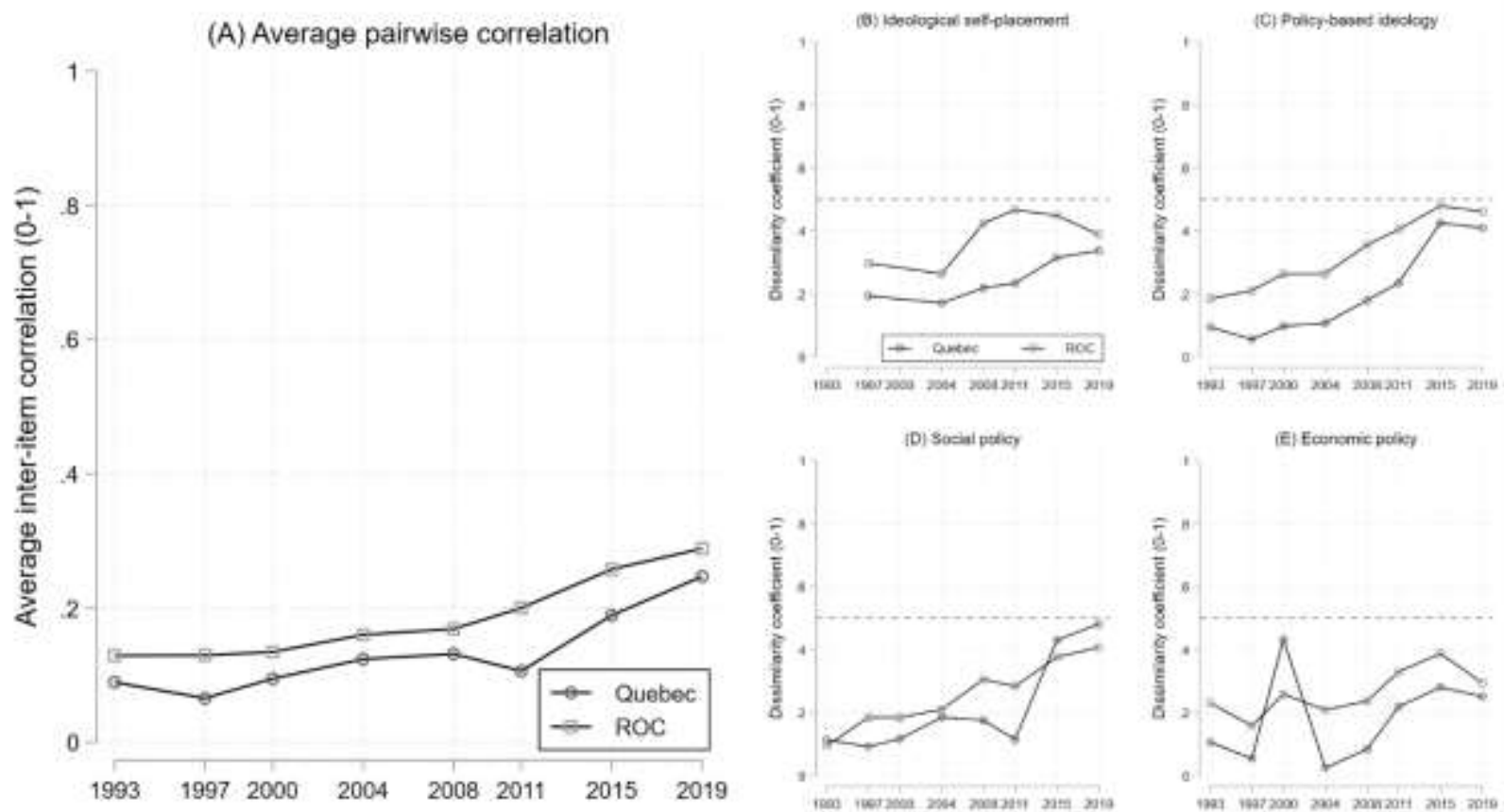

Figure S9. Quebec and Rest-of-Canada differences in the average inter-item correlation (A). Partisan dissimilarity in (B) ideological self-placement; (C) policy-based ideology; (D) social policy; and $(\mathrm{E})$ economic policy. 
(A) Ideological self-placement

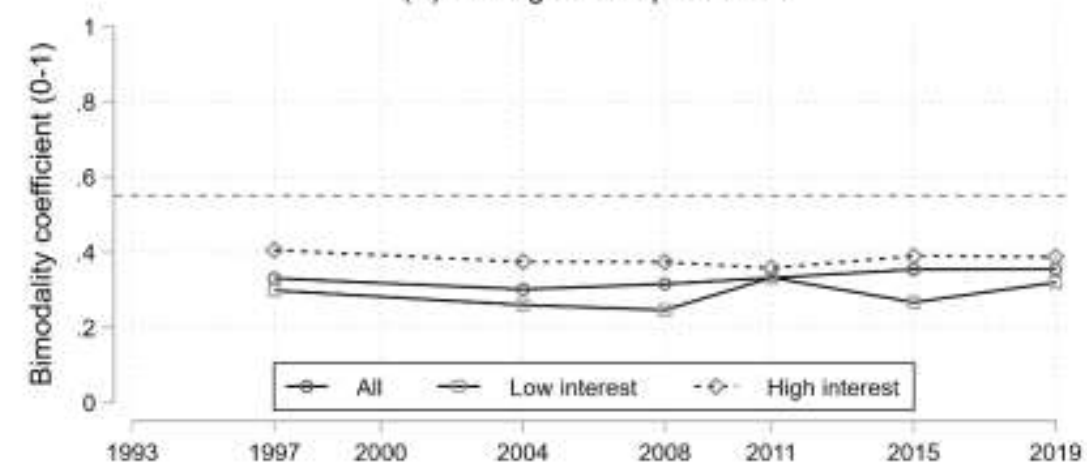

(B) Policy-based ideology

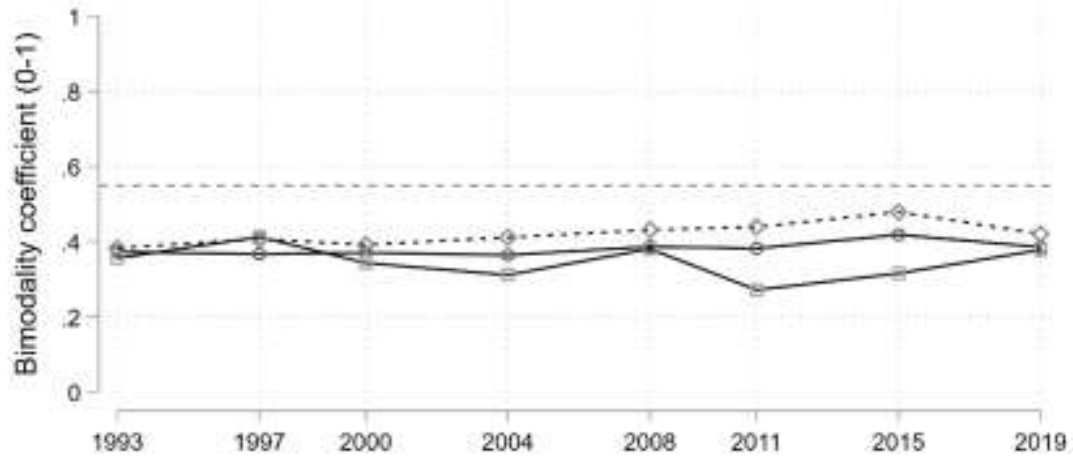

Figure S10. Ideological divergence - weighted. Bimodality coefficients of (A) ideological selfplacement; and (B) policy-based ideology.

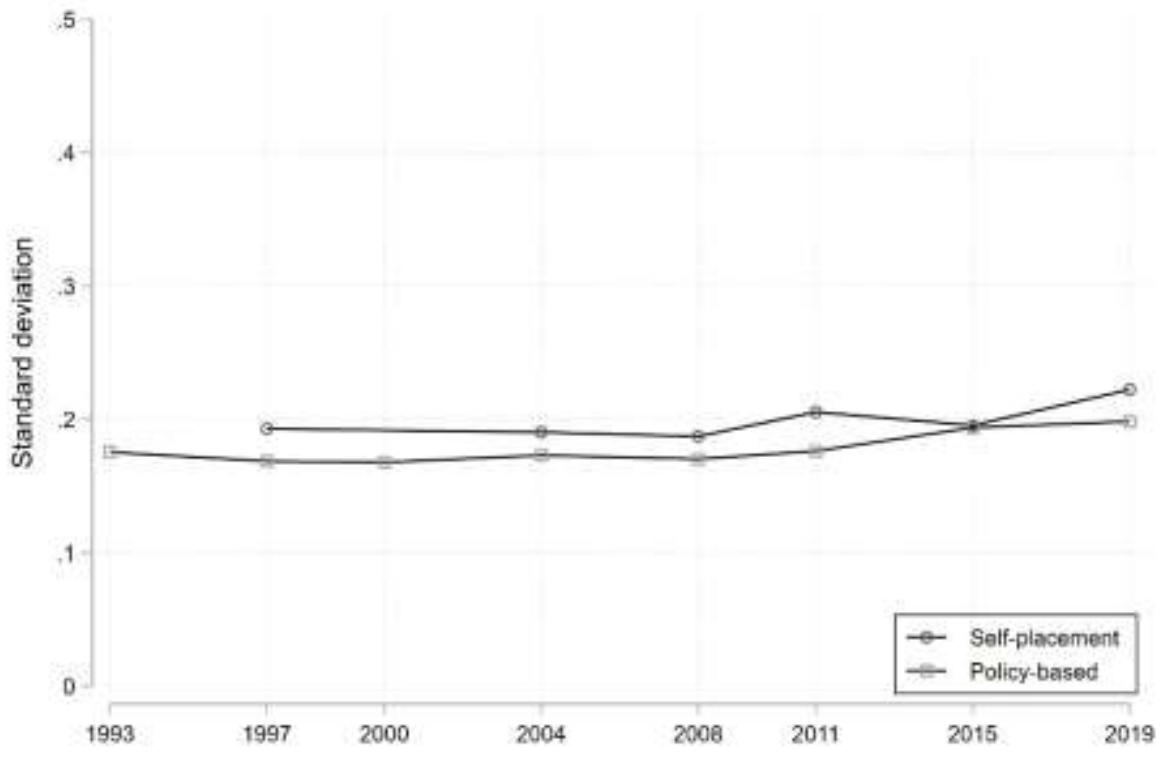

Figure S11. Standard deviations of ideological self-placement and policy-based ideology - weighted. Each ideology measure rescaled from 0-1. 
(A) Average pairwise correlation

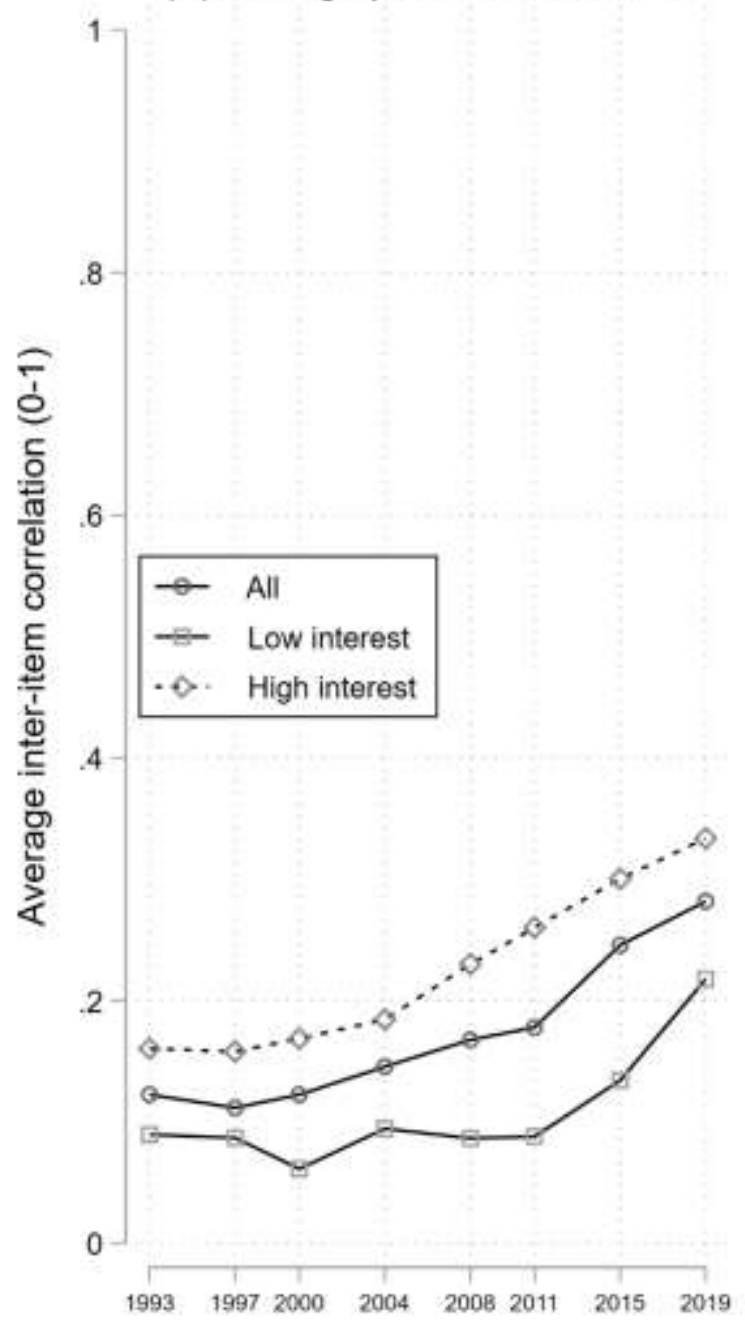

(B) Ideological self-placement

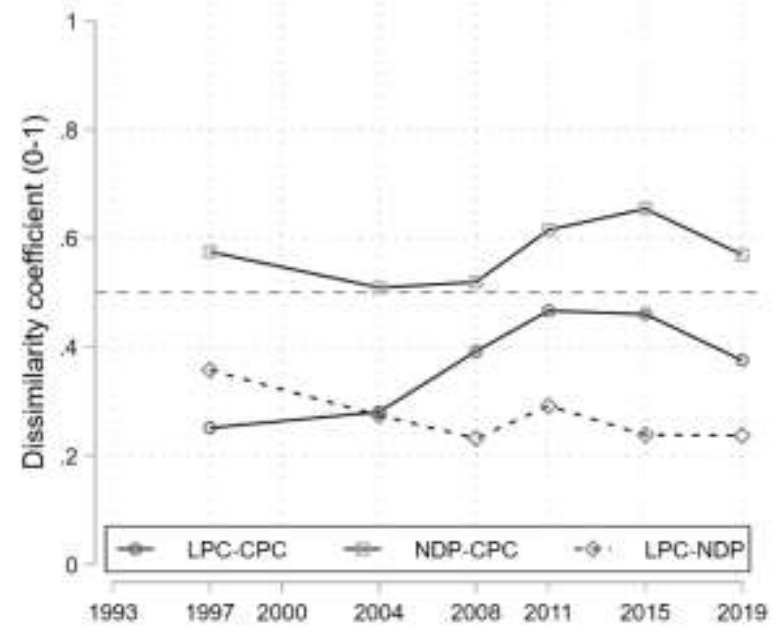

(C) Policy-based ideology

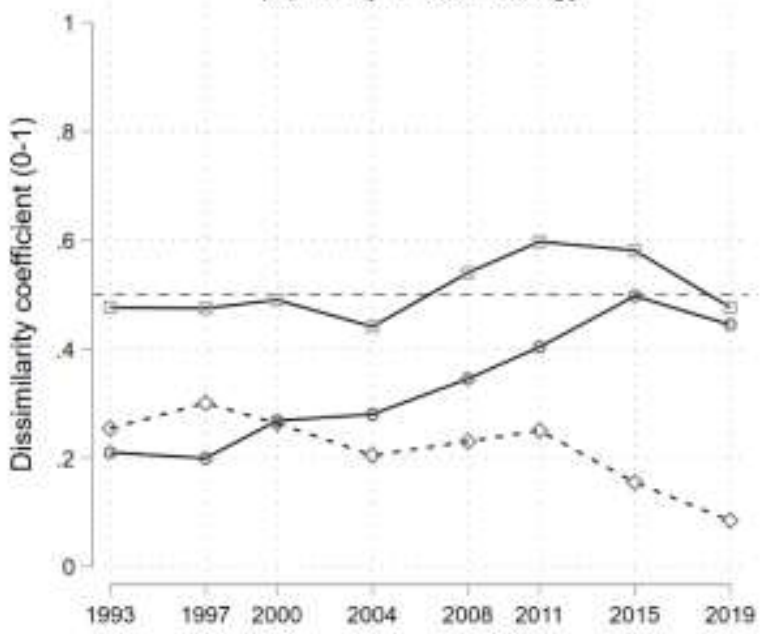

Figure S12. Average inter-item correlation (A). Partisan dissimilarity in (B) ideological selfplacement; (C) policy-based ideology. Using national-level weights. 
Table S3. Rotated factor loadings

\begin{tabular}{lccc}
\hline & 1 & 2 & 3 \\
\hline Immigration & $\mathbf{0 . 5 4}$ & 0.01 & -0.01 \\
Same-sex Marriage & $\mathbf{0 . 3 9}$ & 0.21 & 0.05 \\
Environment & 0.19 & 0.07 & -0.03 \\
Equal Rights & $\mathbf{0 . 4 9}$ & 0.31 & 0.04 \\
Standard of Living & 0.14 & $\mathbf{0 . 5 1}$ & 0.01 \\
Assimilation & $\mathbf{0 . 6 0}$ & 0.09 & -0.01 \\
Inequality & 0.04 & $\mathbf{0 . 4 5}$ & 0.00 \\
Get Ahead & 0.19 & $\mathbf{0 . 3 6}$ & -0.03 \\
\hline
\end{tabular}

Table S4. Comparison of 2019 online and phone results for ideological self-placement

\begin{tabular}{lcc}
\hline & Phone & Online \\
\hline Bimodality Coefficient & 0.35 & 0.39 \\
Standard Deviation & 0.22 & 0.23 \\
Liberal-NDP Dissimilarity & 0.26 & 0.14 \\
NDP-Conservative Dissimilarity & 0.58 & 0.55 \\
Liberal-Conservative Dissimilarity & 0.37 & 0.44 \\
\hline
\end{tabular}


Table S5. Mean ideological scores over time and by party

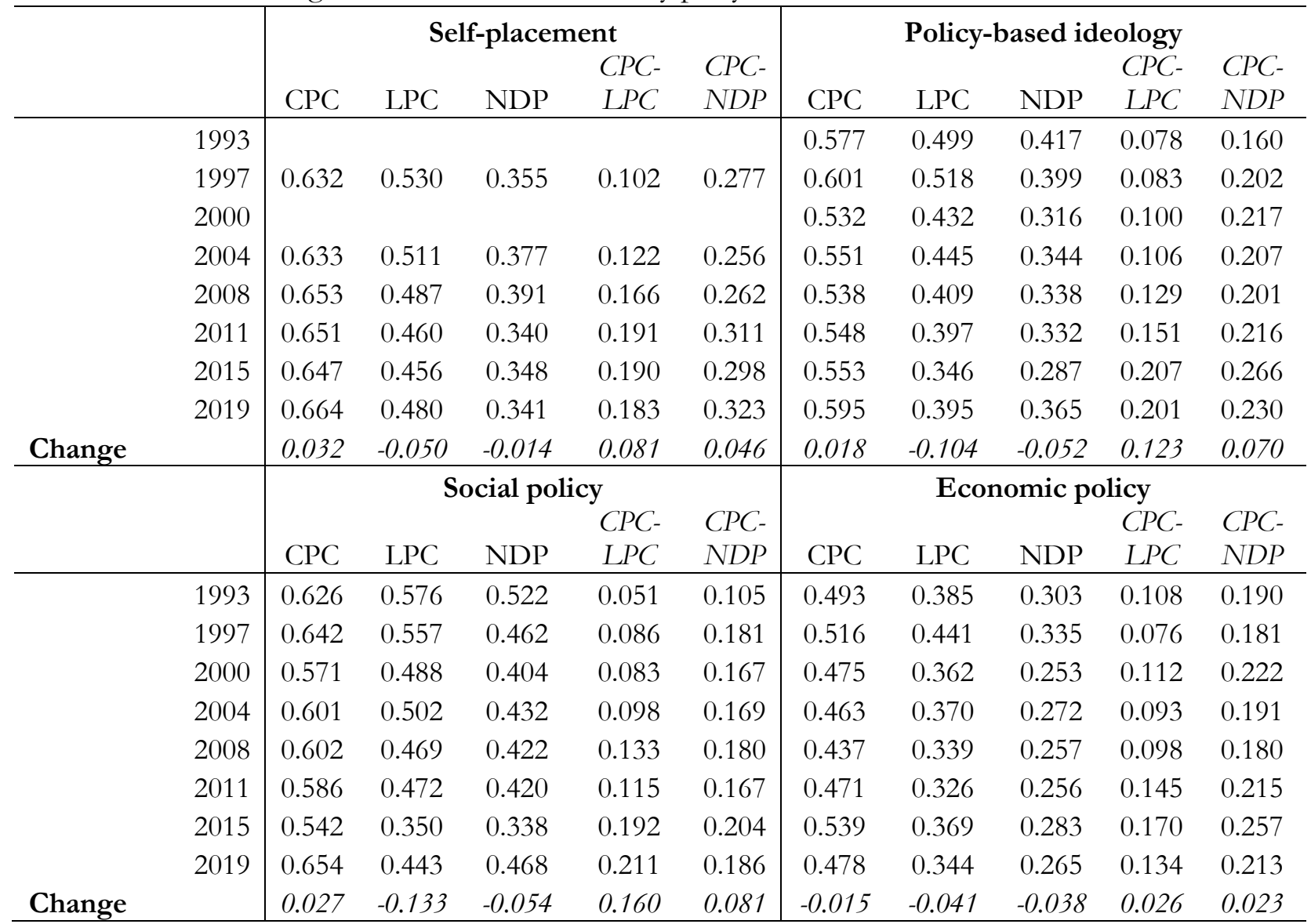

Note: CPC-LPC is the difference between the mean for the Conservatives and Liberals, CPC-NDP is the difference between the mean for the Conservatives and the New Democratic Party. 